\title{
СОЦИАЛЬНАЯ КОММУНИКАЦИЯ И ПАНДЕМИЯ: ПРОБЛЕМЫ ТРАДИЦИОННОГО ОБЩЕНИЯ
}

\section{Ушакова Алина Павловна студент} Научный руководитель: Русанова Анна Алексеевна к.с.н., доцент ФГБОУ ВО «Забайкальский государственный университет»

Аннотация: В статье раскрывается специфика социальной коммуникации в период пандемии. Особое внимание автор уделяет традиционному (личному) общению, его актуальности во время ограничения межличностных контактов. В качестве эмпирической базы использованы материалы Инициативного всероссийского опроса «ВЦИОМ-Спутник» от 28 января 2021.

Ключевые слова: социальная коммуникация, каналы коммуникации, традиционное (личное) общение.

\section{SOCIAL COMMUNICATION AND PANDEMIC: PROBLEMS OF TRADITIONAL COMMUNICATION}

\section{Ushakova Alina Pavlovna Scientific adviser: Rusanova Anna Alekseevna}

\begin{abstract}
The article reveals the specifics of social communication during a pandemic. The author pays special attention to traditional (personal) communication, its relevance during the limitation of interpersonal contacts. The materials of the All-Russian Initiative Survey "VTsIOM-Sputnik" dated January 28, 2021 were used as an empirical base.

Key words: social communication, communication channels, traditional (personal) communication.
\end{abstract}

Социальная коммуникация - это процесс, с помощью которого создается, преобразуется и передается информация между отдельными индивидами, группами людей, различными общественными организациями [1]. Данный процесс нацелен на динамичное развитие, преобразование или 
изменение отношений, знаний, поведения людей для того, чтобы повлиять на индивидов на их системы ценностных ориентаций, интересы. В современной науки социальная коммуникация рассматривается с разных точек зрения.

В социологии существует целое направление, объектом исследования которого является роль и место коммуникации в социальной структуре общества. Предметом же данной отрасли является сама социокоммуникация. У социологии коммуникации существует свой круг задач, основная из которых - изучение процессов передачи информации, а в последствии улучшение механизмов социальных взаимоотношений [2].

Рассуждая над понятием социальная коммуникация Кенецкая В. в соей книги «Социология коммуникации» говорит, что ключевыми словами данной темы являются «общение», «коммуникация», «речевая деятельность» [2]. Причем все три понятия очень часто заменяют друг друга и употребляются как синонимы. Понятие общение зачастую трактуется как обмен информацией, мыслями, тем или иным эмоциональным переживанием общающихся людей. Лингвисты под общением понимают применение коммуникативной функции языка в различных речевых ситуациях, психологи - установление, развитие контактов между людьми во время совместной деятельности, для того чтобы обменяться информацией. Социологи же под общением понимают обусловленный социально определенный вид деятельности людей.

Основоположник теории социального действия социолог Макс Вебер считал, что необходимо изучение прессы в социологическом аспекте, посредством ее ориентации на различные социальные структуры общества. Bce направление понимающей социологии приходит к выводу, что продуктом коммуникации выступает взаимное понимание [3].

Представители символического интеракционизма считают, что с помощью межличностного общения упорядочивается и формируется социальная структура общества, а сам процесс развития коммуникативных форм - это и есть социальное развитие [4]. Чарльз Кули представляет коммуникацию как средство актуализации человеческой мысли, Мид же ставит в центр межиндивидуальное взаимодействие, с помощью которого индивид принимает на себя роль другого, а опыт, накопленный человечеством, становится известным и доступным всем. По мнению Мида, все взаимодействие одновременно формирует отдельного социального индивида и общество в целом. Совершенный действия воспринимаются 
другими индивидами, будучи опосредовано значением, а значение, в свою очередь, это сокращенное взаимодействие, которое существует в опыте людей.

С точки зрения персоналистов коммуникация это «способность личности открывать в себе чувство другого». Данное направление рассматривает общение как процесс взаимопонимания, акт интимных контактов и осознания духовной общности [5]. Например, Ясперс брал в свое понимание возможность общечеловеческой коммуникации в пространстве и времени. С его точки зрения, барьеры культурных коммуникаций преодолеваются с помощью «прочувствования» традиций философии, совокупности мыслей всех времен.

Джон Уотсон, основатель бихевиоризма, ставил в основу коммуникации не сам язык, как систему, конструкцию, а языковые сигналы, манипулируя которыми, возможно влиять на другого человека [6]. Поведение человека Уотсон сопоставлял с системой явных и латентных реакций в схеме «стимул-реакция».

Представитель экзистенциализма А. Камю рассматривал общение индивидов, как процесс, который подчеркивает обособленность и одиночество каждого, в свою очередь, истинное общение между индивидами не существует и невозможно вообще [7].

Дж. Бранз, Э. Ботт, К. Митчел при изучении процессов коммуникации в разных социальных группах распространили такой метод, как анализ социальных сетей, направленный на изучение связей разной интенсивности и плотности, социальных взаимодействий и видов коммуникации [6].

На вопросах передачи информации базируется классическая парадигма коммуникаций, основанная американским политологом, социологом $Г$. Лассуэлом. Автор считает, что в социальной коммуникации доминирует коммуникативный аспект массовой коммуникации, а информационный содержательный элемент выполняет лишь латентную функцию [8].

Представители конструктивистского направления Т. Лукман, П. Бергер основывались на феноменологической социологии философа, социолога А. Шюца, рассматривающего действие как цель осуществления коммуникации. По мнению Шюца, язык - главный механизм построения социальной коммуникации [9].

Пьер Бурдье, так же являющийся представителем социологической модели коммуникации, не приближен к собственно вербальной 
коммуникации - он описывает контекст - «габитус», предопределяющий определенные символические действия. Ученый следил за тем, как мнение социальных классов распределяется через газеты, журналы и др. Социолог говорил: «Политика является исключительно благодатным местом для эффективной символической деятельности, понимаемой как действия, осуществляемые с помощью знаков, способных производить социальной, и, в частности, группы» [10]. Итак, Бурдье рассматривал политическую коммуникацию, которая осуществляется в символической плоскости. При том коммуникация является «действующей силой», позволяющей реализовать себя власти и политикам.

Нельзя не затронуть во внимание яркого представителя феноменологической методологии Ю. Хабермаса, который рассматривал межличностные интеракции как инструмент реализации различных интересов людей, как способ отхождения от политических, экономических и прочих влияний, искажающих коммуникации и играющих вспомогательную роль принуждения [11]. Общение индивидов друг с другом, по мнению Хабермаса, конструирует фундамент для гражданского общества с помощью развития коммуникативных отношений и реализации систем массовых коммуникаций.

Юзеф Подгорецки в своей статье «Социальная коммуникация - наука века» анализирует множество определений понятия коммуникация [12] и приходит к выводу, что это:

1. Средство взаимодействия различных объектов материального и духовного мира;

2. Процесс общения (передача информации от индивида к индивиду);

3. Обмен и передачи информации в социуме в целях воздействия на него.

В современном обществе коммуникация осуществляется везде: между индивидами, социальными группами, организациями, культурами, государствами и носит уже давно глобальный характер. Между людьми данный процесс протекает в основном в традиционном формате - общение лицом к лицу, с целью обмена знаковыми сообщениями, в которых отображены идеи, мысли, знания, ценностные отношения, эмоциональное состояние. В современных условиях социальная коммуникация играет существенную роль в обществе, осуществляя получение различной информации неограниченному кругу людей, использующих ее в своих целях. 
Несомненно, «удаленная коммуникация» позволяет передавать текст, звук, изображение, видео и многое другое, но готово ли человечество в настоящее время полностью уйти на удаленный режим общения?

За основу эмпирической базы данной работы взят анализ данных Инициативного всероссийского опроса «ВЦИОМ-Спутник» (28 января 2021 г.), в котором возможно найти ответы на следующие вопросы: перестали ли поддерживаться обычными способами семейные узы, дружеские связи, рабочие отношения в период пандемии Covid-19, какое место личное общение заняло в жизни россиян в это нелегкое время.

В опросе приняли участие 1600 человек в возрасте от 18-ти лет, проживающих во всех регионах Российской Федерации. Метод опроса телефонное интервью.

Результаты опроса позволили выстроить рейтинг популярности способов общения у россиян (см. Рис. 1). Личное общение вошло в ТОП-3 наиболее используемых каналов коммуникации: мобильный телефон, онлайн-переписка и личное общение [16].

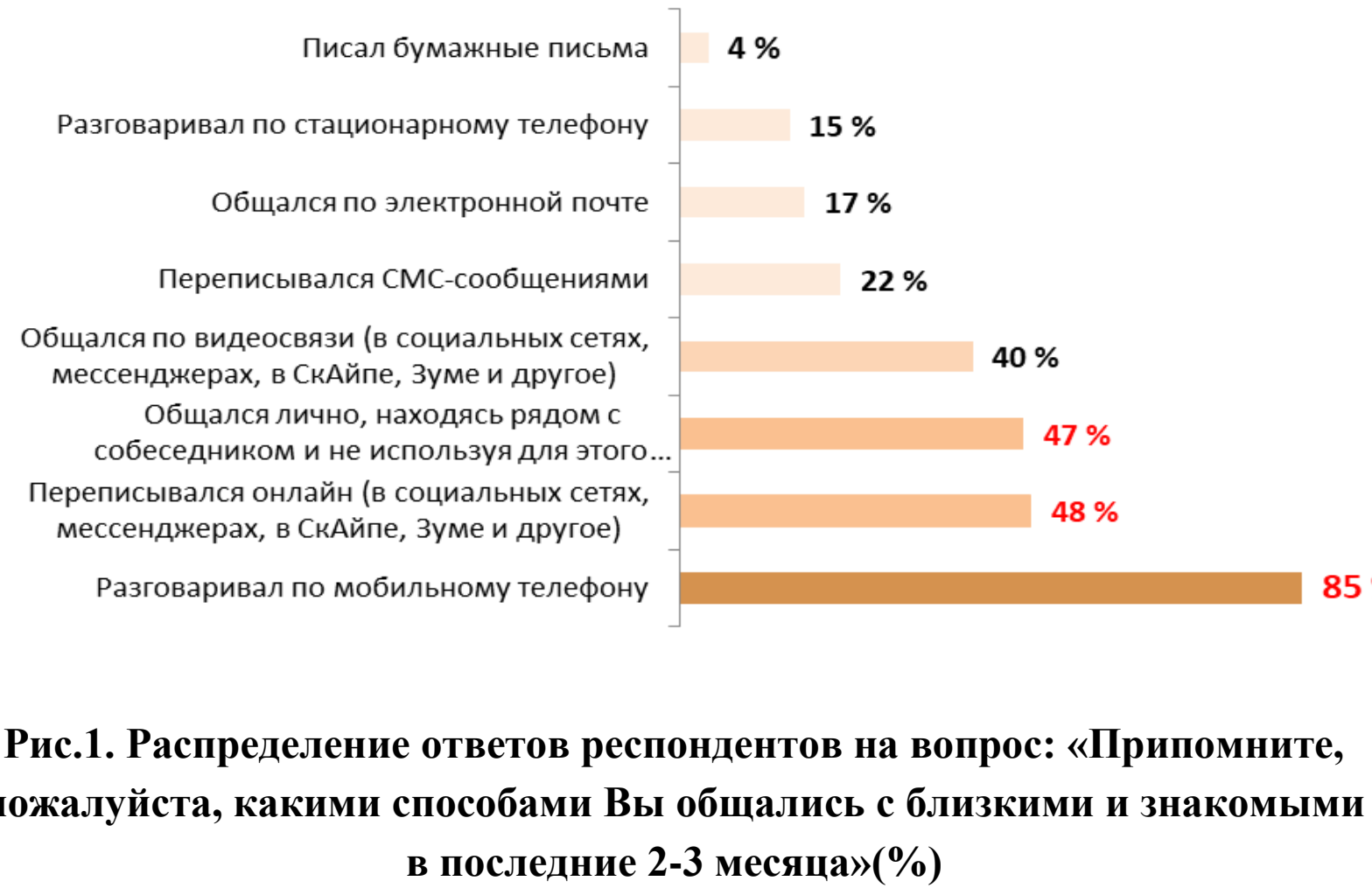

Как видим, позиция «общался лично, находясь рядом с собеседником и не использую для этого электронные устройства» придерживалась почти половина респондентов (47\%) [16]. Причем, не отмечается каких-то особых 
гендерных различий, зато по возрастному критерию этот показатель снижается пропорционально повышению возраста респондентов.

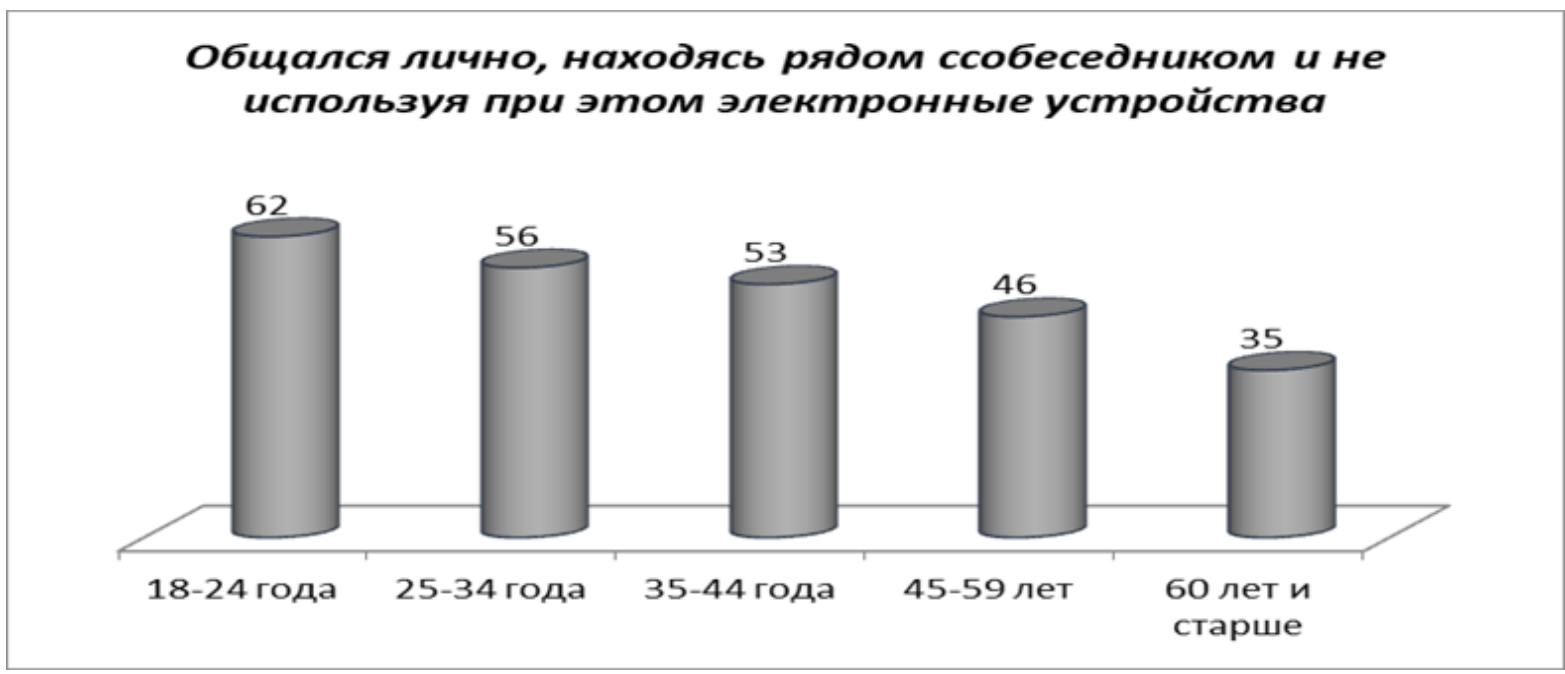

Рис. 2. Позиция «Общался лично, находясь рядом с собеседником и не используя для этого электронные устройства» / Возраст (\%)

В качестве объяснения этой тенденции можно привести два аргумента:

- несоблюдение молодыми людьми тех рекомендаций и рамок, в которые поставила нас пандемия,

- режим самоизоляции людей старше 60 лет.

Существует определенный стереотип, что в небольших населенных пунктах люди больше приближены друг к другу не только территориально, но и социально: близкое соседство, все друг друга знают, широкие родственные связи и т.д. Такое тесное взаимодействие, как правило, способствует и традиционному личному общению, которое, согласно этой логике, должно преобладать, в первую очередь, в сельских поселениях. Ведь люди, проживающие в такой местности, более коммуникабельны по отношению друг к другу и общаются лично больше, чем горожане. Сравнительный анализ ответов респондентов-сельчан и городских жителей позволяет опровергнуть этот стереотип [16]. В результате был получен обратный эффект: жители сельской местности лично общались с близкими и знакомыми в последние 2-3 месяца гораздо меньше, чем горожане (см. Рис. 3). 


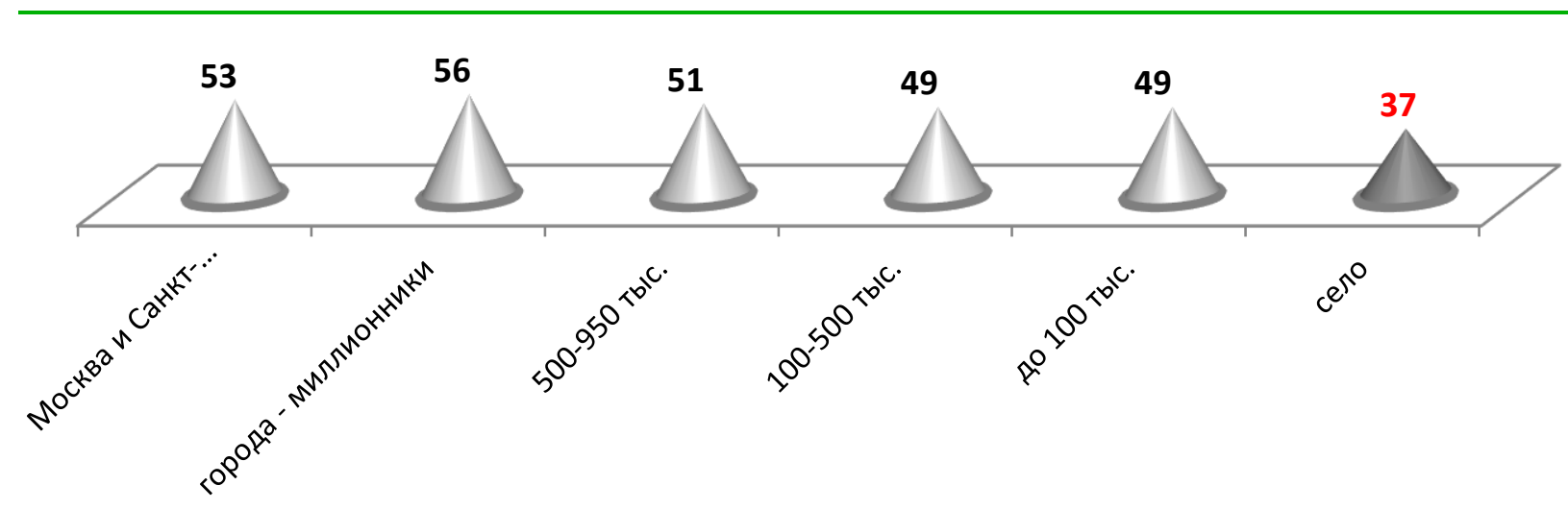

\section{Рис. 3. Позиция «Общался лично, находясь рядом с собеседником и не используя для этого электронные устройства» / тип населенного пункта (\%)}

Предположительно, данное распределение можно объяснить следующим образом:

- высокая коммуникабельность и интеграция городских жителей в большом, слабо контролируемом пространстве, способствующая нарушению короновирусных мер,

- ответственное принятие серьезных рисков пандемии сельскими жителями.

Было выявлено, что традиционным способом (лично) больше всего респонденты общаются с коллегами по работе. Это вполне объяснимо, так как определенные профессиональные вопросы зачастую необходимо решать только в личном контакте, в том числе минусами являются и то, что размыты границы рабочего дня, невозможность полной отвлеченности от домашних дел, в принципе сложное взаимодействие с коллегами. На втором месте оказалось общение с близкими друзьями, которое можно объяснить тем, что в тяжелое время самоизоляции людям просто необходимо избавиться от состояния одиночества, тревожности, беспокойства. И ради этого некоторые нарушали дистанционный режим общения.

Самыми близкими и значимыми для нас людьми являются родители, и с одной стороны, положительно, что личное общение с ними сохранилось у каждого четвертого респондента, причем, эти контакты преобладают в возрастных группах от 18 до 45 лет [16]. Меньше всех общаются с родителями люди старше 60 лет, что можно объяснить спецификой этой возрастной группы: у ее представителей их уже может не быть (см. Рис. 4). 


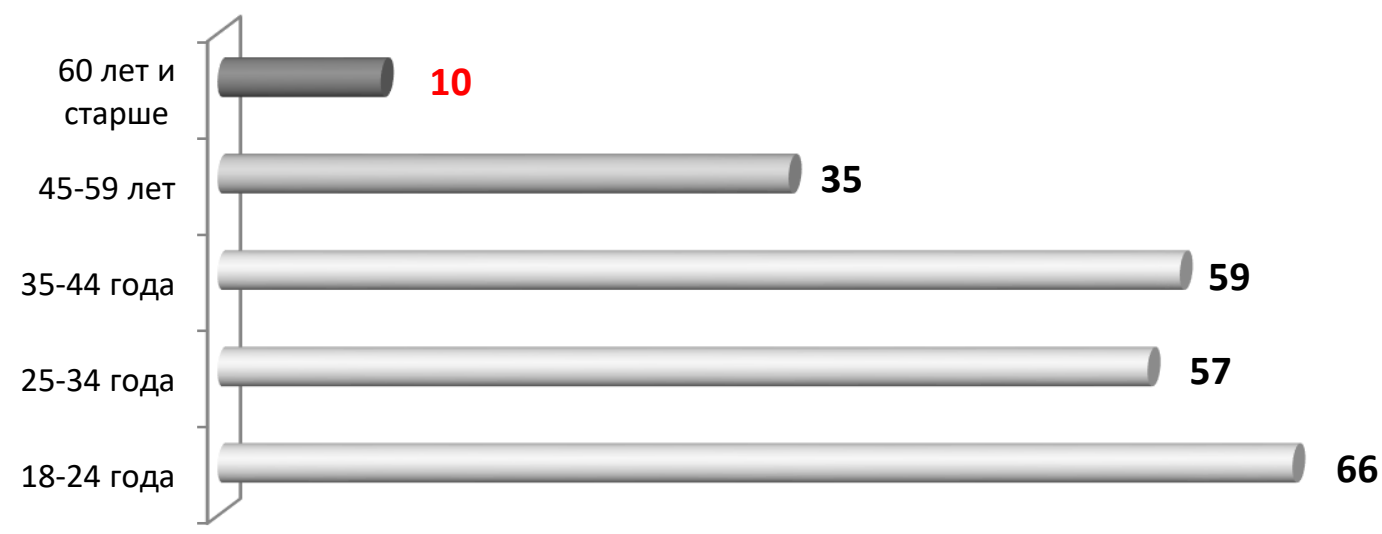

\section{Рис. 4. Распределение ответов респондентов по возрасту на вопрос «Скажите, пожалуйста, а каким образом Вы чаще всего общаетесь с родителями» / позиция «Общался лично, находясь рядом с собеседником и не используя для этого электронные устройства» (\%)}

Итак, традиционное (личное) общение, несмотря на ограничительные меры, связанные с пандемией, сохранилось в жизни россиян. Оно занимает третье место после общения по мобильному телефону и онлайн-переписки. Эта тенденция сохраняется во всех социально-демографических и территориальных группах. Традиционного вида общения придерживается почти половина всех опрошенных респондентов. Из этого следует, что современное общество, не смотря на высокое развитие интернет-технологий, современных способов связи даже в ограниченных условиях общения не способно полностью отойти от традиционной социальной коммуникации.

Социология коммуникации изучает процессы передачи информации, а в последствие улучшает механизмы социальных взаимоотношений. И мы надеемся, что создание, преобразование и передача информации между различными компонентами общества будет происходить в большей степени традиционным путем. Именно традиционные каналы общения способствуют более динамичному и прогрессивному развитию личности человека.

\section{Список литературы}

1. Адамьянц Т.3. Социальные коммуникации : учебник для академического бакалавриата. - 2-е изд., перераб. и доп. - М. : Издательство Юрайт, 2018. - 200 с.

2. Кенецкая В. Социология коммуникаций [Электронный ресурс] Режим доступа: https://www.gumer.info/bibliotek_Buks/Sociolog/koneck/ 
intro.php - (дата обращения: 10.05.21)

3. Скворцова Е. А. Проблема методологии исследования феномена массовых коммуникаций (на примере социологии М. Вебера) [Электронный pecypc] - Режим доступа: https://cyberleninka.ru/article/n/problema-metodologiiissledovaniya-fenomena-massovyh-kommunikatsiy-na-primere-sotsiologii-mvebera - (дата обращения: 10.05.21)

4. Горшкова Е. А. Интеракционисткий подход Кули к определению предмета и метода социальной психологии [Электронный ресурс] - Режим доступа: https://cyberleninka.ru/article/n/interaktsionistskiy-podhod-ch-h-kuli-kopredeleniyu-predmeta-i-metoda-sotsialnoy-psihologii - (дата обращения: 11.05.21)

5. Белозёров А. Б. Понятие коммуникации в экзистенциальной философии К. Яспера [Электронный ресурс] - Режим доступа: https://cyberleninka.ru/article/n/ponyatie-kommunikatsii-v-ekzistentsialnoyfilosofii-k-yaspersa - (дата обращения: 11.05.21)

6. Песоцкий В. А., Жебит В. А. Дао коммуникалогии, или долгий путь к метапарадигме социальной коммуникации [Электронный ресурс] - Режим доступа: https://cyberleninka.ru/article/n/dao-kommunikologii-ili-dolgiy-put-kmetaparadigme-sotsialnoy-kommunikatsii - (дата обращения: 11.05.21)

7. Горохов П. А. Некоторые мысли о философии Альбера Камю [Электронный pecypc] - Режим доступа: https://cyberleninka.ru/article/ n/nekotorye-mysli-o-filosofii-albera-kamyu - (дата обращения: 11.05.21)

8. Воронцов С. Г. Модель коммуникации Г. Д. Лассуэла как элемент методологии цивилистических исследований [Электронный ресурс] - Режим доступа: https://cyberleninka.ru/article/n/model-kommunikatsii-g-d-lassuela-kakelement-metodologii-tsivilisticheskih-issledovaniy - (дата обращения: 11.05.21)

9. Ненашев М. И. Идеи социальной феноменологии Альфреда Шюца [Электронный pecypc] - Режим доступа: https://cyberleninka.ru/article/n/ideisotsialnoy-fenomenologii-alfreda-shyutsa - (дата обращения: 11.05.21)

10. Колянова А. Ю. О «псевдокоммуникации» и политической журналистике: читая Пьера Бурдье [Электронный ресурс] - Режим доступа: https://cyberleninka.ru/article/n/o-psevdokommunikatsii-i-politicheskoyzhurnalistike-chitaya-piera-burdie - (дата обращения: 11.05.21)

11. Весечко Е. Н. Юрген Хабермас и его теория коммуникативного действия [Электронный ресурс] - Режим доступа: https://cyberleninka.ru 
/article/n/yurgen-habermas-i-ego-teoriya-kommunikativnogo-deystviya - (дата обращения: 11.05.21)

12. Подгорецки Ю. Социальная коммуникация - наука века [Электронный pecypc] - Режим доступа: https://cyberleninka.ru/article/n/ sotsialnaya-kommunikatsiya-nauka-xxi-veka - (дата обращения: 11.05.21)

13. Волков Ю. Г., Курбатов В. И. Глобальная социология пандемии: отечественные и зарубежные сценарии и тренды послекоронавирусного мира // Гуманитарий Юга России. 2020. Том. 9. № 2. С. 17-32.

14. Горшков М.К. Пандемия очищает небосвод [Электронный ресурс] - Режим доступа: https://lgz.ru/article/_17-18-6735-29-04-2020/pandemiyaochishchaet-nebosvod-/ - (дата обращения: 20.03.21)

15. Добров Е., Сысоев Т. 15 образов мира после короновируса [Электронный ресурс] - Режим доступа: http://www.sib-science.info/ru/news/ 15-obrazov-mira-posle-koronav-06042020 - (дата обращения: 22.03.21)

16. Инициативный всероссийский опрос ВЦИОМ-Спутник (28 января 2021) [Электронный pecypc] - Режим доступа: https://old.wciom.ru/ index.php?id=236\&uid=10693 - (дата обращения: 27.02 .21 )

(C) А.П. Ушакова, 2021 